\title{
A Histopathological study of eyelid lesions at a tertiary care Hospital
}

\author{
Vivek Naik $^{1}$, Suresh Mandrekar ${ }^{2 *}$, Sangeeta Amoncar ${ }^{3}$, R.G. Wiseman Pinto ${ }^{4}$ \\ ${ }^{\mathbf{1}}$ Associate Professor, ${ }^{2}$ Assistant Professor, ${ }^{3}$ Lecturer, ${ }^{4}$ Professor and HOD, ${ }^{1}$ Dept. of Ophthalmology, ${ }^{2-3}$ Dept. of Pathology, Goa Medical \\ College, Goa, India
}

\section{Article Info}

Received: $28^{\text {th }}$ February, 2019

Accepted: $11^{\text {th }}$ April, 2019

Published Online: $9^{\text {th }}$ September, 2019

Keywords: Benign, Eyelid, Lesions, Malignant.

\begin{abstract}
Introduction: Eyelids are affected by a variety of benign and malignant conditions. A clinical diagnosis is not always correct and hence a histo-pathological study of the lesions is necessary to arrive at correct diagnosis.

Aims and Objectives: To study the prevalence of various eyelid lesions at a teaching hospital and to compare the same with other studies.

Materials and Methods: The study was conducted over a seven year period from January 2009 to December 2015 at Goa Medical College, Bambolim Goa. A total of 100 patients who presented to the Ophthalmology and Plastic surgery department with eyelid lesions and who were operated were included. Histopathological examination of the excised specimens was conducted using standard processing technique and taking 5 micron sections and staining by Hematoxylin and Eosin technique.

Results: A total of 100 lesions were studied, of which 50(50\%) were non-neoplastic and $50(50 \%)$ were neoplastic which included $41(41 \%)$ benign tumors and $9(9 \%)$ malignant tumors. The age group ranged from 2 to 85 years with the youngest patients ( 2 patients who were 2 yrs old) presenting with pyogenic granuloma and a dermoid cyst of the eyelid respectively and the oldest was a 85 year old female with intradermal melanocytic naevus of Left upper eyelid.
\end{abstract}

\section{Introduction}

Eyelids have a cutaneous and conjunctival portion with a variety of tissues. ${ }^{1}$ Skin appendages of eyelids include the sebaceous glands (glands of Zeiss and Meibomian glands), apocrine glands (glands of Moll) and eccrine sweat glands (Wolfring and Krause glands). These along with eyelash follicles and cells of epidermis can give rise to tumours. ${ }^{2}$

Eyelids can be affected by a variety of lesions which may be inflammatory or neoplastic. An eyelid mass could be aesthetically disturbing to the patient as well as diagnostically difficult for the attending primary care physicians. $^{3}$

Eyelid tumors are the most frequent neoplasms in ophthalmological practice and include a large variety of benign tumors as well as a few malignant tumors. ${ }^{4}$

The prevalence of various eyelid malignancies show a geographical variation which is believed to be the result of environmental factors including sunlight and ultraviolet exposure..$^{5}$ Although many types of eyelid tumors can be diagnosed clinically some can be diagnosed only with pathological specimens. ${ }^{2}$

The objective of this study is to assess the prevalence of various eyelid lesions on histopathology and compare them with other studies from India and other countries.

\section{Materials and Methods}

This study is an analysis of 100 eyelid lesions, which were excised surgically and subjected to histopathological examination. The study was conducted over a seven year period at Goa Medical College, a tertiary care hospital. Most of the cases were referred by department of Ophthalmology and some by the department of Plastic Surgery. The patients' clinical data was retrieved from Histopathology requisition form with respect to Age, Sex, location i.e. upper or lower eyelid and laterality i.e. right eye or left eye. The specimens were processed for paraffin sectioning and 5 micron thick sections were obtained and stained with hematoxylin and eosin stain. The data was tabulated and the results were compared with those from other studies from India and abroad.

\section{Results}

A total of 100 specimens of eyelid lesions that were excised were received over the study period of 7 years. The lesions were categorized into non-neoplastic 50(50\%), benign tumors $41(41 \%)$ and malignant tumors $9(9 \%)$.

The histopathological spectrum of various Non neoplastic lesions encountered and their relative frequencies are shown in Table 1. Amongst the non-neoplastic lesions cystic lesions were most commonly encountered which

\footnotetext{
*Corresponding Author: Suresh Mandrekar, Assistant Professor, Dept. of Pathology, Goa Medical College, Goa, India Email: sureshmandrekar@ymail.com http://doi.org/10.18231/j.ijceo.2019.083
} 
included Epidermal cyst (14 cases), hydrocystoma (6 cases) and Dermoid cysts (5 cases). A chronic non specific inflammatory reaction was observed in 8 cases and 6 cases of chalazion (lipogranuloma) were seen.

The frequency and spectrum of various benign tumors is shown in Table 2. capillary hemangioma was the commonest benign tumor encountered (13 cases) followed by intradermal naevus ( 9 cases) and squamous papilloma ( 8 cases).

The histopathological diagnosis of 9 malignant tumors encountered is shown in Table 3. Basal cell carcinoma and Sebaceous carcinoma were the commonest tumors seen with frequency of 3 cases each.

The age distribution of the eyelid lesions ranged from 2 years to 85 years. The youngest patients were 2 years old; one with dermoid cyst of the right upper eyelid and the other with pyogenic granuloma of right upper eyelid. The oldest patient was 85 year old female with intradermal melanocytic naevus of left upper eyelid.

With respect to sex distribution, 53(53\%) cases were seen in males and $47(47 \%)$ in females. There was an equal distribution of neoplastic cases both benign and malignant in both the sexes, whereas the non neoplastic lesions were more predominant in male patients.

Topographically the right eye was involved in 62 cases and the left eye in 37 cases and one case of xanthelesma involved both the eyes (Table 4).

Upper eyelid was involved in 80 cases and the lower one in 20 cases. Thus all non neoplastic, benign as well as malignant lesions were more often seen in upper eyelid (Table 4)

The malignant tumors were more often encountered in upper eyelid 7/9 and also all the cases of sebaceous gland carcinoma were seen in the upper eyelid.
Table 1: Histopathological spectrum of non- neoplastic eyelid lesions

\begin{tabular}{|l|c|}
\hline Non-neoplastic Lesions & Number \\
\hline Epidermal cyst & 14 \\
\hline Chronic non specific inflammation & 08 \\
\hline Chalazion(Lipogranuloma) & 06 \\
\hline Hydrocystoma & 06 \\
\hline Dermoid cyst & 06 \\
\hline Fibrous polyp & 03 \\
\hline Seborrheic kaeratosis & 03 \\
\hline Molluscum contagiosum & 01 \\
\hline Parasitic granuloma & 01 \\
\hline Xanthelesma & 01 \\
\hline Organising Hematoma & 01 \\
\hline Total & $\mathbf{5 0}$ \\
\hline
\end{tabular}

Table 2: The frequency and spectrum of benign tumors

\begin{tabular}{|l|c|}
\hline Benign tumors & Number \\
\hline Capillary hemangioma (Pyogenic granuloma) & 13 \\
\hline Intradermal melanocytic naevus & 09 \\
\hline Squamous Papilloma & 08 \\
\hline Benign skin adnexal tumors & 05 \\
\hline Neurofibroma & 03 \\
\hline Neurilemoma & 01 \\
\hline Myxoma & 01 \\
\hline Lipoma & 01 \\
\hline Total & $\mathbf{4 1}$ \\
\hline
\end{tabular}

Table 3: The histopathological spectrum of malignant tumors

\begin{tabular}{|l|c|}
\hline Malignant tumors & Number \\
\hline Basal cell carcinoma & 03 \\
\hline Sebaceous carcinoma & 03 \\
\hline Squamous cell carcinoma & 02 \\
\hline Adenoid cystic carcinoma & 01 \\
\hline Total & 09 \\
\hline
\end{tabular}

Table 4: The distribution of the eyelid lesions with reference to laterality and eyelid involvement

\begin{tabular}{|c|c|c|c|c|c|}
\hline \multirow{2}{*}{ Location } & Upper & \multicolumn{3}{|c|}{ Lesion } & \multirow{2}{*}{ Total } \\
\cline { 2 - 6 } & Lower & Non neoplastic & Benign tumors & Malignant tumors & \\
\hline \multirow{3}{*}{ Lid } & Upper & 42 & 31 & 07 & 80 \\
\cline { 2 - 6 } & Lower & 08 & 10 & 02 & 20 \\
\hline \multirow{2}{*}{ Eye } & Right & 31 & 26 & 05 & 62 \\
\cline { 2 - 6 } & Left & 18 & 15 & 04 & 37 \\
\cline { 2 - 6 } & Both & 01 & 00 & 00 & 01 \\
\hline
\end{tabular}

Table 5: Comparison of data of eyelid lesions from various studies

\begin{tabular}{|c|c|c|c|c|}
\hline Study & Length of study(years) & Total no of cases & Benign cases (\%) & Malignant cases (\%) \\
\hline Ref 1* & 7 & 238 & $144(60.50)$ & $87(36.55)$ \\
\hline Ref 4 & 8 & 471 & $216(45.8)$ & $255(54.2)$ \\
\hline Ref 6 & 4 & 855 & $649(76)$ & $206(24)$ \\
\hline Ref 7 & 5 & 144 & $126(87.5)$ & $18(12.5)$ \\
\hline Ref 8 & 1 & 57 & $45(79)$ & $12(21)$ \\
\hline Ref 10 & $21 / 2$ & 86 & $45(52.3)$ & $41(47.7)$ \\
\hline Ref11 & 2 & 100 & $61(61)$ & $39(39)$ \\
\hline Present study & 7 & 100 & $91(91)$ & $9(9)$ \\
\hline
\end{tabular}


*Seven cases of premalignant lesions not included

Table 6: Comparison of data of malignant tumors in different studies

\begin{tabular}{|c|c|c|c|c|c|c|}
\hline Study & Total malignant & \multicolumn{5}{|c|}{ No. of cases of malignant tumors } \\
\cline { 3 - 7 } & cases & BCC & SCC & SGC & MM & Others \\
\hline Ref 1(Pakistan) & 87 & 49 & 18 & 13 & 1 & 6 \\
\hline Ref 2 (Turkey) & 22 & 21 & 1 & - & - & - \\
\hline Ref3(Hong Kong) & 25 & 12 & 5 & 2 & 2 & 4 \\
\hline Ref 4 (Romania) & 255 & 185 & 50 & 5 & 15 & - \\
\hline Ref 5(Iran) & 100 & 83 & 8 & 6 & 2 & 1 \\
\hline Ref 7 (Taiwan) & 18 & 14 & 1 & 3 & - & - \\
\hline Ref 8(India) & 12 & 04 & 01 & 05 & 02 & - \\
\hline Ref 10(India) & 41 & 11 & 09 & 17 & 01 & 3 \\
\hline Ref 11(India) & 39 & 16 & 4 & 16 & 3 & - \\
\hline Ref 12(India) & 27 & 12 & 4 & 10 & - & 1 \\
\hline Ref 13(Pakistan) & 222 & 131 & 70 & 15 & 3 & 3 \\
\hline Present study(India) & 9 & 3 & 2 & 3 & - & 1 \\
\hline
\end{tabular}

\section{Discussion}

A review of various studies published on eyelid lesions in the literature, revealed that various authors have used different schemes to categorize the lesions. Some have divided the lesions into just two broad categories of benign and malignant. ${ }^{3,5-7}$ Other authors have included the category of Pseudotumors (Non-neoplastic lesions) ${ }^{4}$ and still others have added a category of pre-malignant lesions ${ }^{1}$ and thus made four categories. In the present study we have divided the eyelid lesions into three categories namely; nonneoplastic, benign tumors and malignant tumors. A comparison of the incidence of benign and malignant cases from various published studies is shown in Table 5.

In our study among the non- neoplastic lesions, Cysts (Hydrocystomas) were the commonest lesions with inclusion cysts or epidermal cysts being the most common (14 cases); followed by cysts of glands of Zeis and Moll (6 cases) and dermoid cysts (5 cases). Other studies have also shown similar findings with cysts as the most common lesion. ${ }^{1,4}$ Dermoid cyst was the commonest reported lesion in one study from India. ${ }^{8}$ Sweat gland hydrocystoma was reported to be the commonest benign lesion accounting for 65(29.3\%) cases in a study from Saudi Arabia. ${ }^{9}$ A study from Turkey reported 164 cases of Hydrocystoma of the eyelid. ${ }^{2}$

Although chalazion is the commonest lesion presenting as a mass lesion in the eyelid; not all cases of chalazion are subjected for histopathological examination and hence may not represent its true incidence. A chalazion is histopathologically seen as a lipogranuloma. In our study we found 6 cases of chalazion/lipogranulomas, second in frequency to the benign cysts. A study from Saudi ${ }^{9}$ has reported 45 cases of chalazion out of 222 eyelid lesions and a similar incidence has been found in other studies. ${ }^{1}$

As far as the benign tumors of the eyelid are concerned, Capillary hemangioma (Pyogenic granuloma) was the commonest tumor reported (13 cases), followed by intradermal melanocytic naevus ( 9 cases) and squamous papilloma ( 8 cases). A similar incidence has been reported amongst benign tumors from other Indian studies wherein melanocytic naevi were the dominant tumors ${ }^{3,5,7-11}$ or squamous papillomas were more often seen. ${ }^{2}$ Thus hemangiomas, melanocytic naevi and Squamous papillomas are the commonest benign neoplasms of the eyelid. We encountered one case of myxoma of the eyelid. Another study from India ${ }^{10}$ has described 3 cases of cutaneous myxoma amongst the eyelid tumors.

We encountered 5 cases of benign skin adnexal tumors of the eyelid which included sebaceous adenoma (1) Eccrine acrospiroma (1), pleomorphic adenoma (1), trichoepithelioma (1) and one skin adnexal tumor which could not be categorized. Skin appendageal tumors have also been encountered by other authors. ${ }^{1}$ In a study from Turkey, ${ }^{2}$ skin adnexal tumors accounted for $202(13.1 \%$ ) of cases whereas a study from Tehran ${ }^{5}$ has reported 10 cases of benign cutaneous adnexal tumors out of 182 cases.

Amongst the malignant tumors of the eyelid, we encountered 3 cases each of sebaceous gland carcinoma and basal cell carcinoma. Other studies from India have also revealed either sebaceous carcinoma $^{8,10}$ or basal cell carcinoma ${ }^{12}$ occurring as the most predominant malignant tumor or both sebaceous and basal cell carcinoma occuring with equal frequency ${ }^{11}$ like in our study. However studies from Pakistan which is a neighboring country have shown basal cell carcinoma as the most prevalent eyelid tumor followed by squamous cell carcinoma. ${ }^{1,13}$

Studies from other parts of the world also revealed basal cell carcinoma as the most prevalent eyelid malignancy followed by squamous cell carcinoma ${ }^{2-5}$ except a study from Taiwan ${ }^{7}$ which showed Sebaceous gland carcinoma as the second most common malignancy of the eyelid. (Table 6)

Sebaceous carcinoma is more often seen in the upper eyelid may be because of the more number of meibomian glands in the upper eyelid. Sebaceous gland carcinoma is known as a masquerader as it may mimic benign eyelid conditions like chalazion and may be missed if the specimen is not subjected for histopathology. Hence it is essential to submit all specimens especially from recurrent chalazion for 
histopathological examination. Moreover a study of 1502 cases from Turkey did not report a single case of sebaceous carcinoma. $^{2}$

In the present study all the three cases of sebaceous carcinoma were seen in the upper eyelid in accordance with the literature. Although sebaceous carcinoma has been more often reported in females as compared to males, in the present study two of the three patients were males.

\section{Source of Funding: None.}

\section{Conflict of Interest: None.}

\section{References}

1. Farhat F, Jamal Q, Saeed M, Ghaffar Z. Evaluation of eyelid lesions at a tertiary care hospital, Jinnah Postgraduate Medical Centre(JPMC) Karachi. Pak J Ophthalmol. 2010;26:83-6.

2. Gundogan FC, Yolcu U, Tas A, Sahin OF, Ozun S, Cermik H et al. Eyelid tumors: clinical data from an eye centre in Ankara Turkey. Asian Pac J Cancer Prev. 2015;16:4265-9.

3. Ho M, Liu DTL, Chong KKL, Ng HK, Lam DSC. Eyelid tumors and pseudotumors in Hong-Kong a ten year experience. Hong Kong Med J 2013;19:150-5.

4. Coroi MC, Rosca E, Mutiu G, Coroi T, Bonta M. Eyelid tumors: histopathological and clinical study performed in country hospital of Oradea between 2000-2007. Romanian J Morphol Embryol. 2010;51:111-5.

5. Bagheri A, Tavakoli T Kanaani A, Zavareh RB, Esfandiari H, Aletaha HS. Eyelid masses: a 10 year survey from a tertiary eye hospital in Tehran. Middle East Afr J Ophthalmol. 2013;20:187-92.
6. Paul S, Vo DT, Silkiss RZ. Malignant and benign eyelid lesions in San Francisco study of diverse urban population. Am J Clin Med. 2011;8:40-6.

7. Chang CH, Chang SH, Lai YH, Huang J, Su MY, Wang HZ et al. Eyelid tumors in Southern Taiwan: A 5 year survey from a Medical University. Kaohsung J Med Sci. 2003;19:549-54.

8. Chauhan SJ, Shah SJ, Patel AB, Rathod HK, Surve SD, Nasit JG. A histopathological study of ophthalmic lesions at a teaching hospital. Natl J Med Res. 2012;2:133-6.

9. Al-Faky YH. Epidemiology of benign eyelid lesions in patients presenting to a teaching hospital. Saudi J Ophthalmol. 2012;26:211-6.

10. Ramya BS, Biligi D, Clinmayee JT, Raghupathi AR. Tumors of the eyelid-A histopathological study of 86 cases in a tertiary hospital. Int J Sci Res Publications. 2014;4:1-5.

11. Rathod A, Pandharpurkar M, Toopalli K, Bele S. A clinicopathological study of eyelid tumors and its management at a tertiary eye care centre of Southern India. MRIMS J Health Sci. 2015; 3:54-7.

12. Jahagirdar S, Thakre TP, Kale SM, Kulkarni H, Mamtani M. A clinicopathological study of eyelid malignancies from central India. Indian J Ophthalmol. 2007;55:109-12.

13. Hussain I, Khan FM, Alam M, Khan BS. Clinicopathological analysis of malignant eyelid tumors in North-West Pakistan. JPMA 2013;63:25-7.

How to cite this article: Naik V, Mandrekar S, Amoncar S, Pinto RGW. A Histopathological study of eyelid lesions at a tertiary care Hospital. Indian J Clin Exp Ophthalmol 2019;5(3):348-51. 